\title{
Arginine-Stimulated Acute Phase of Insulin and Glucagon Secretion in Diabetic Subjects
}

\author{
Jerry P. Palmer, James W. Benson, Robert M. Walter, and \\ JOHN W. ENSINCK \\ From the Department of Medicine and Diabetes Center, University of Washington \\ School of Medicine, Seattle, Washington 98195
}

A в S T R A C T To determine if both phases of glucagon secretion are excessive in diabetes, arginine was administered intravenously as pulses and as infusions to normal subjects, insulin-dependent diabetics, and noninsulin-requiring diabetics. The acute phase of glucagon secretion, in response to arginine pulses at four different doses (submaximal to maximal $\alpha$-cell stimulating), was indistinguishable in terms of timing, peak levels attained, and total increments comparing controls and diabetics. During the first half of the arginine infusion $(500 \mathrm{mg} /$ $\mathrm{kg}$ over $30 \mathrm{~min}$ ) the glucagon rise in controls and diabetics was similar $(P>0.1)$, whereas during the last half of the infusion excessive glucagon levels were seen in the diabetics. No difference in the glucagon responses to arginine administered as either a pulse or an infusion was observed between the two types of diabetics. The acute phase responses of insulin to intravenous, maximal stimulating doses of glucose $(20 \mathrm{~g})$ and arginine $(2.5 \mathrm{~g})$ were measured in five insulin-independent diabetics. Although the acute insulin response to arginine was normal, there was marked attentuation of the early $\beta$-cell response upon stimulation by glucose. From these results we conclude that although in diabetes excessive glucagon levels are observed with chronic arginine stimulation, the acute phase of glucagon secretion in response to arginine is normal. In addition, the $\beta$-cell in noninsulin-requiring diabetics, although acutely hy-

This work was presented in part at the 33rd Annual Meeting of the American Diabetes Association, Chicago, Ill., 1973.

Dr. Palmer was the recipient of a National Institutes of Health Research Fellowship (1F22 AMO 1342-01) while conducting this research.

Dr. Walter's present address is Department of Internal Medicine, School of Medicine, University of California, Davis, Calif. 95616.

Received for publication 19 January 1976 and in revised form 19 May 1976. poresponsive to glucose, remains normally responsive to another stimulus, arginine.

\section{INTRODUCTION}

Multiple studies have demonstrated the biphasic nature of insulin and glucagon secretion during continuous exposure to a variety of stimuli (1-6). Some adult-onset diabetic patients appear to have a selective inability to secrete insulin immediately upon stimulation with glucose, even though the acute phase insulin response to isoproterenol (7), tolbutamide (8), glucagon (9), and secretin (10) is preserved. This defect in glucose-stimulated insulin release may be specific for the first phase of secretion, since with prolonged glucose infusion, insulin stimulation has been reported to be normal in adult-onset diabetics $(11,12)$. Other investigators have disagreed that this defect is specific for first phase secretion and have observed that both phases of insulin release in response to glucose are diminished in diabetics (6). The hypothesis that this deficient early insulin secretory response to glucose may play an important role in the carbohydrate intolerance of adult-onset diabetes is supported by additional experimental observations. We and others have shown a high correlation between the acute phase of insulin secretion and glucose disposal rate during an intravenous glucose tolerance test in nondiabetic young people $(13,14)$. In diabetic patients and dogs when insulin was administered by a computerized insulin delivery system (artificial pancreas), the pattern of injections required simulation of the acute phase of insulin secretion to completely normalize carbohydrate tolerance $(15,16)$.

During an arginine infusion in nondiabetic man, portal vein glucagon shows a biphasic secretory pattern (3), but separation of the two phases is not observed in the peripheral plasma. We have previously employed 
arginine administered intravenously as a pulse rather than as an infusion to quantitate the acute phase of glucagon and insulin secretion in peripheral blood of normal man (17). In this paper we have used the same technique in juvenile and adult-onset diabetic patients to evaluate their acute phase insulin and glucagon secretion. Also, the glucagon levels during arginine infusions have been evaluated with attempts made to separate the early and late responses.

\section{METHODS}

\section{Subjects}

The 33 subjects who served as controls were healthy, male volunteers 18-35 yr old, with fasting plasma glucose concentrations less than $100 \mathrm{mg} / \mathrm{dl}$ and no family history of diabetes mellitus. 30 of the control subjects were within $10 \%$ ideal body weight. Ideal body weight was calculated from the range of weights for medium frame adults (18). Six insulin-dependent diabetics, four females and two males, aged 22-67 yr (mean age, $38 \mathrm{yr}$ ), who had each required insulin treatment for over $4 \mathrm{yr}$ to prevent metabolic decompensation, with weights ranging from 100 to $148 \%$ ideal body weight $($ mean $=123 \%)$ were also studied. 8 of the 10 diabetics not requiring insulin treatment had fasting plasma glucose levels greater than $125 \mathrm{mg} / \mathrm{dl}$, while the other 2 had 2 -h oral glucose tolerance tests with plasma glucose concentrations of 220 and $200 \mathrm{mg} / \mathrm{dl}$. None were receiving oral hypoglycemic medications. The body weights of these 10 diabetics ranged from 100 to $157 \%$ ideal body weight $($ mean $=114 \%)$. This group included seven males and three females, aged 22-67 yr (mean age, $49 \mathrm{yr}$ ). Subjects were informed of the nature, purpose, and potential risks before their voluntary participation.

\section{Study protocol}

All tests began between 8 and 9 a.m. after an overnight fast without specific antecedent dietary preparations. Insulin-dependent diabetics omitted their morning insulin dose before the studies and had received their last dose the preceding morning. Blood was withdrawn and glucose and arginine injected by scalp-vein needles in the subject's antecubital veins. Patency of these lines was maintained by the slow infusion of normal saline.

Arginine pulse. Arginine hydrochloride solution (5 or $10 \%$ ) in doses of $0.6,1.25,2.5$, and $5.0 \mathrm{~g}$ was administered intravenously over $30 \mathrm{~s}$, with blood withdrawn every 2 min (in some cases also at 3 and $5 \mathrm{~min}$ ) after the arginine injection for the first $10 \mathrm{~min}$ and then at 15,20 , and $30 \mathrm{~min}$. $\mathrm{U}_{\mathrm{p}}$ to four doses of arginine in succession were administered to some subjects on a single morning. Each dose was separated by at least $30 \mathrm{~min}$, and if different doses were injected the smaller dose preceded the larger. We have previously demonstrated that both maximal and submaximal stimulating doses of arginine given every $30 \mathrm{~min}$ elicit successive immunoreactive glucagon (IRG) ${ }^{1}$ and immunoreactive insulin (IRI) responses that are the same in terms of timing, magnitude, and absolute peak values (17).

Arginine infusion. Arginine hydrochloride solution (5 or $10 \%$ ) in a dose of $500 \mathrm{mg} / \mathrm{kg}$ was administered intravenously over 30 min by a Holter pump (Extracorporeal Medical

${ }^{1}$ Abbreriations used in this paper: IRG, immunoreactive glucagon; IRI, immunoreactive insulin.
Specialties Inc., King of Prussia, Pa.). Blood samples were obtained at $2,3,4,5,6,8$, and $10 \mathrm{~min}$ after starting the infusion, every $5 \mathrm{~min}$ thereafter until $50 \mathrm{~min}$, and then at 10-15min intervals to $90 \mathrm{~min}$.

Glucose pulse. $20 \mathrm{~g}$ of $50 \%$ dextrose was injected intravenously over $30 \mathrm{~s}$ with the timing of blood sampling the same as described for the arginine pulse.

Each study was preceded by a $1-h$ control period during which four base-line specimens were obtained. All blood specimens after drawing were transferred to heparinized tubes, immediately placed on ice, separated by centrifugation within $30 \mathrm{~min}$ of collection, and then frozen at $-20^{\circ} \mathrm{C}$ until assayed. Benzamidine was used to prevent glucagon degradation.

\section{Determinations}

IRI was measured by double-antibody radioimmunoassay (19). In our IRG assay we extracted each specimen with acetone, used benzamidine at a final concentration of $0.01 \mathrm{M}$, employed antiserum $30 \mathrm{~K}$, and separated bound from free antibody by cellulose adsorption. Details of this assay have been published $(20)$.

\section{Analysis of data}

The acute glucagon and insulin response to arginine and the acute insulin response to glucose are expressed as the respective IRG and IRI areas above basal for the $10 \mathrm{~min}$ after administration of the stimulus. Basal is the mean level of the four samples drawn over $1 \mathrm{~h}$ preceding the arginine or glucose injection; or for consecutive arginine pulses, as the mean of the 20 - and 30 -min values from the preceding pulse plus the zero time value for the pulse under consideration. The slope of the line of best fit for the IRG response from basal to $5 \mathrm{~min}$ and from 5 to $30 \mathrm{~min}$ during the arginine infusion was calculated. Conventional statistical analyses (21), IRG and IRI areas, and straight line formulas were calculated on a Wang model 600 computer (Wang Laboratories, Inc., Tewksbury, Mass.).

\section{RESULTS}

The acute phase IRG and IRI responses of the diabetic patients and the control volunteers to a maximal stimulating dose of arginine $(5 \mathrm{~g})$ are shown in Fig. 1. The IRI data pertains only to the insulin-independent diabetic subjects, whereas the IRG responses from both insulin-dependent and insulin-independent patients have been combined since no differences between these two types of diabetes were observed. In our control subjects there was an abrupt rise in IRG and IRI, with peak levels being attained at 2-4 min after arginine injection, followed by a rapid decline. In the diabetics the IRG and IRI responses to the arginine pulse were virtually identical to those observed in the controls showing no difference in terms of timing of response, peak levels attained, or total acute phase response (area 0-10 min).

We have previously shown that the dose-response curve for the acute phase of IRG and IRI by this technique ranges from $0.1-0.3$ to $2.5-5.0 \mathrm{~g}$ of arginine (17). Fig. 2 depicts the IRG and IRI areas $0-10 \mathrm{~min}$ in the diabetic and control subjects at four different doses on this dose-response curve. Irrespective of arginine dose 


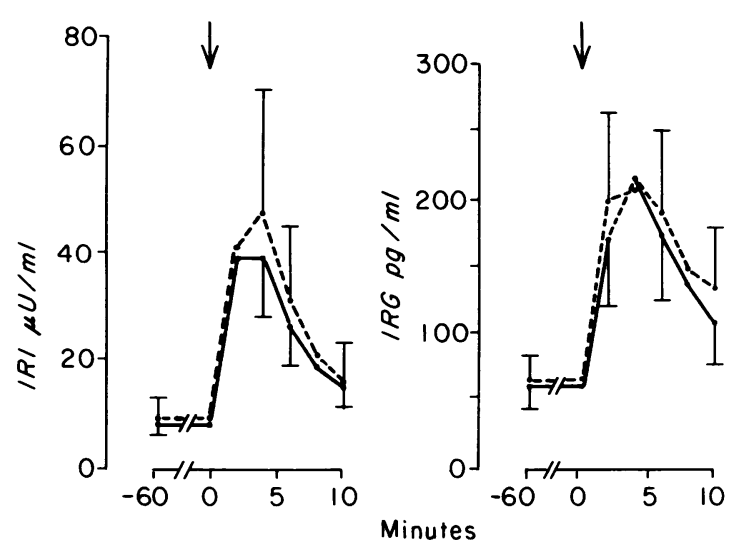

FIGURE 1 IRG and IRI responses, mean \pm SEM, to $5.0 \mathrm{~g}$ arginine given at zero time in 12 control subjects (-) and diabetic patients (-- ). IRI levels are from insulinindependent diabetics $(n=5)$ and IRG values are from both insulin-independent and insulin-requiring diabetics ( $n$ $=10$ ).

the glucagon response in the diabetics could not be distinguished from that in the nondiabetics. In addition, comparison of IRG area $(0-10 \mathrm{~min})$ for each dose in insulin-dependent vs. insulin-independent diabetics or each type of diabetic separately vs. control volunteers
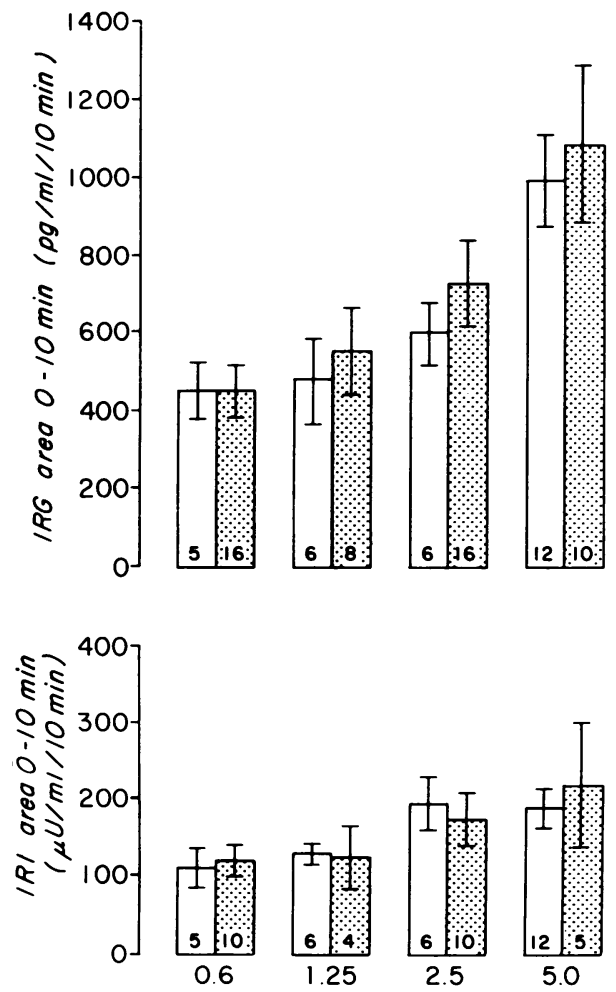

Figure 2 IRG and IRI, mean \pm SEM, dose response to intravenous arginine in controls (plain) and diabetics (stippled). Numbers below graph refer to dose of arginine in grams and numbers within bar graphs represent the number of subjects receiving each dose.
TABLE I

Comparison of the IRG Area, 0-10 Min, in the Two Types of Diabetics and Normal Controls

\begin{tabular}{lcccc}
\hline & \multicolumn{4}{c}{ Arginine dose } \\
\cline { 2 - 5 } & $0.6 \mathrm{~g}$ & $1.25 \mathrm{~g}$ & $2.5 \mathrm{~g}$ & $5.0 \mathrm{~g}$ \\
\hline & \multicolumn{4}{c}{$\mathrm{pg} / \mathrm{ml} / 10 \mathrm{~min}^{*}$} \\
$\begin{array}{c}\text { Noninsulin- } \\
\text { treated diabetics }\end{array}$ & $491 \pm 226$ & $723 \pm 332$ & $888 \pm 454$ & $1.233 \pm 640$ \\
$\begin{array}{c}\text { Insulin-dependent } \\
\text { diabetics }\end{array}$ & $304 \pm 226$ & $372 \pm 196$ & $451 \pm 280$ & $846 \pm 613$ \\
$\begin{array}{c}\text { Nondiabetic } \\
\text { controls }\end{array}$ & $451 \pm 160$ & $474 \pm 246$ & $596 \pm 194$ & $990 \pm 398$ \\
\hline
\end{tabular}

* Mean \pm SD.

showed no differences (Table I). The mean acute phase IRI release at the four doses of arginine in the insulinindependent diabetics was not different from the mean response in the nondiabetic volunteers.

Because our control and diabetic subjects were not age, weight, and sex matched, we performed regression analyses of IRG area $0-10 \mathrm{~min}$ vs. age and vs. percentage of ideal body weight in the diabetics at the two doses of arginine that we had administered to the largest number of subjects, 0.6 and $2.5 \mathrm{~g}$. No significant correlations were observed $(r<0.2, P>0.05)$. In addition, comparison of the IRG area $0-10 \mathrm{~min}$ at these two doses in males vs. females revealed no differences $(P>0.05)$.

11 of the diabetic patients, 6 insulin dependent and 5 insulin independent, also received arginine infusions (Fig. 3). Despite frequent sampling, the biphasic nature of the IRG response could not be appreciated from the peripheral levels in the controls or the diabetics. When compared with the controls the IRG response of the

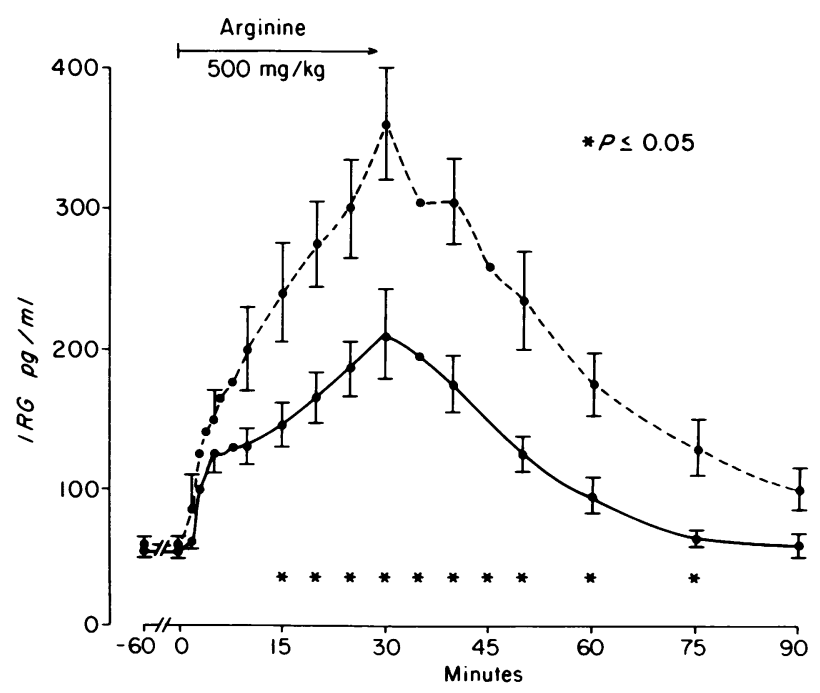

Figure 3 IRG responses, mean \pm SEM, to 30 -min arginine infusions in 7 control subjects $(-)$ and in 11 diabetic patients (-- ). 


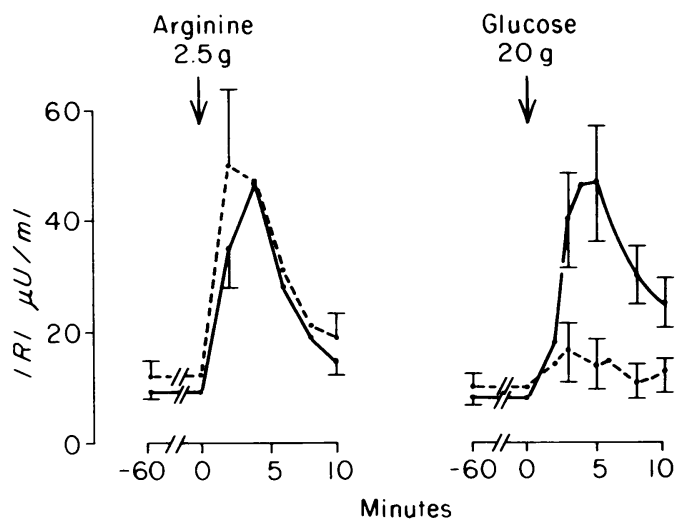

FIgURE 4 IRI responses, mean \pm SEM, to intravenous injections of arginine and glucose over $20-30 \mathrm{~s}$ in five diabetics not requiring insulin treatment (-- ) and in normal volunteers $(-), n=7$ for glucose and $n=6$ for arginine stimulation in control subjects.

diabetics was normal for the first $10 \mathrm{~min}$ of the infusion, but after $15 \mathrm{~min}$ an exaggerated response was detected. The total IRG rise during the arginine infusion in the diabetics, expressed as IRG area 0-90 min, was markedly elevated compared to the response in the nondiabetics, $(13,096 \pm 1,832$ vs. $6,302 \pm 905 \mathrm{pg} / \mathrm{ml}$ per 90 min, respectively $[P<0.005])$. In contrast, there was no difference in the early secretory response, (IRG area 0-10 $\mathrm{min})$, between diabetic and control volunteers, $(832 \pm 148$ vs. $515 \pm 89 \mathrm{pg} / \mathrm{ml}$ per $10 \mathrm{~min}$, respectively). The IRG areas (0-10 and 0-90 min) of the two types of diabetics were not different. Since there appeared to be a change in the rate of increment in the IRG response curve during the arginine infusion at $5 \mathrm{~min}$ in the control subjects, and since the acute glucagon response to an arginine pulse peaks at 4-5 min (17). we analyzed the slope of the IRG response from 0 to $5 \mathrm{~min}$ and from 5 to 30 min during the arginine infusion. The 0-5-min slopes were the same in the diabetic and nondiabetic subjects. but the 5-30-min slopes were markedly disparate $(P=0.005)$.

Fig. 4 compares the acute phase of insulin secretion in five insulin-independent diabetics who received maximal stimulating doses of arginine $(2.5 \mathrm{~g})$ and glucose $(20.0$ g) to the responses in normal controls. Four of the diabetics had fasting plasma glucose levels greater than $200 \mathrm{mg} / \mathrm{dl}$; the fasting plasma glucose in the fifth diabetic was $112 \mathrm{mg} / \mathrm{dl}$ with a 2 -h oral glucose tolerance test value of $220 \mathrm{mg} / \mathrm{dl}$. Although the IRI response to arginine was normal in these diabetics, they displayed a marked attenuation of their IRI response to glucose $(P=0.005)$.

\section{DISCUSSION}

In man portal venous measurements have demonstrated that the $\alpha$-cell secretory response to an arginine infusion is biphasic (3). In our study and in the one reported by Blackard et al. (3), peripheral samples were obtained every 1-2 $\mathrm{min}$. Therefore, the inability to detect two phases of glucagon release in peripheral blood cannot be attributed to inadequate frequency of sampling, but may be due to other factors such as dilution in the circulating blood volume and(or) hepatic extraction. Plasma IRG, as measured by radioimmunoassay using antiserum $30 \mathrm{~K}$. is composed of at least four different fractions on gel filtration with a variable percentage $(25-75 \%)$ eluting as glucagon with a mol wt of 3.500 daltons (22). Only the species of IRG with mol wt of 3,500 and 9,000 daltons vary when $\alpha$-cell secretion is stimulated or suppressed (22). In two separate studies the ratios of portal to peripheral venous concentration of basal IRG were reported to be $1.3 \pm 0.1$ and $1.7 \pm 0.5$. respectively (23,3). however no fractionation of total glucagon immunoreactivity $(30 \mathrm{~K})$ was undertaken. It is possible that hepatic extraction of the IRG species of $3.500 \mathrm{~mol} w \mathrm{wt}$ is considerably greater and thereby accounts for the lack of a biphasic secretory pattern in peripheral plasma. Using the arginine pulse technique established previously in normals to investigate early phase IRG responses (17). this study demonstrates no difference between diabetics and normals at four doses of arginine ranging from submaximal to maximal stimulatory doses. Furthermore, no difference was found between insulin-requiring and noninsulin-treated diabetics. In 11 of these diabetic subjects who received an arginine infusion. hyperglucagonemia was observed only during the last half of the infusion. which appears to be consistent with the IRG pattern in diabetic man and animals reported by others (24. 25$)$.

IVe consider the area $0-10$ min during an arginine infusion to reflect primarily the acute component of $\alpha$-cell secretion. which is analogous temporally to the early insulin response to glucose (4). Thorell et al. have reported that the area $0-10 \mathrm{~min}$ is the best method of estimating the early insulin response to glucose from peripheral IRI determinations (26). Since the acute phase IRG and IRI responses to an arginine pulse were virtually identical in terms of timing. it is reasonable to assume that the area $0-10 \mathrm{~min}$ represents mainly the early phase of glucagon secretion. Also we have shown IRI area $0-10 \mathrm{~min}$ to be strongly correlated $(r=0.99)$ with $\Delta 3^{\prime}-5^{\prime}$ IRI (13), another common method of expressing acute phase release. Since the maximal IRG level after an arginine pulse occurs at 4-5 min, we have considered the rate of rise of IRG during the first $5 \mathrm{~min}$ of the arginine infusion to reflect primarily first phase secretion, whereas the later rise, 5-30 min. probably reflects an integration of residual first phase plus second phase. This division of the IRG response is based on a two phase model. In the diabetics both the area 
0-10 min and IRG slope $0-5$ min during the arginine infusion were indistinguishable from the values in the nondiabetic controls, whereas the 5-30-min slope and the total IRG response, area 0-90 min, were clearly increased in the diabetics. Although we did not measure glucose concentrations during the arginine infusions, others have documented a small rise in nondiabetics which is exaggerated in juvenile-type diabetics (25). Since hyperglycemia does not suppress glucagon secretion in diabetics $(25,27)$, during the second half of the arginine infusion diabetic $\alpha$-cells would not be influenced by the rising glucose levels whereas there would be a suppressive effect in the nondiabetics. In other words, the hyperglucagonemia we observed in the diabetics late in the arginine infusion may not so much be due to excessive stimulation of late phase secretion but more to lack of $\alpha$-cell inhibition by the rising glucose levels.

A marked attenuation of glucose-stimulated acute phase insulin secretion in adult onset diabetics with preservation of this secretory phase to other stimuli has been observed by others $(7-10)$. Fajans et al. reported that in diabetics, during separate arginine and glucose infusions, there appeared to be less attenuation of the early IRI response to arginine than to glucose, although clear separation of first and second phases was not possible (4). The use of the arginine pulse technique to stimulate early phase insulin release verifies that in insulinindependent diabetics, whose $\beta$-cell response to glucose is markedly diminished, the ability to acutely release insulin in response to arginine is maintained. It may be that this diminished early insulin secretion upon stimulation with glucose accounts for the delay in rise of insulin levels after oral glucose that has been observed in adult-onset diabetics (28), and contributes to their carbohydrate intolerance. One could argue that the diabetics should be compared to nondiabetics at a similar plasma glucose level. Normal volunteers made hyperglycemic have marked potentiation of their acute IRI response to an arginine pulse (17), but their basal insulin level at the time of arginine stimulation is elevated from prior stimulation by the raised plasma glucose concentration. The administration of the arginine pulse after an overnight fast allows both groups, diabetic and nondiabetic, to be studied in the basal state. Since only the diabetics' $\beta$-cells are insensitive to glucose, comparison of the two groups of subjects at comparable degrees of hyperglycemia would result in double stimulation of the nondiabetics' $\beta$-cells (glucose plus arginine) and single stimulation in the diabetic (arginine).

It has been proposed that in diabetes both the $\alpha$ - and $\beta$-cells are insensitive to regulation of their secretion by glucose (29). Although the IRG suppression by hyperglycemia and stimulation by hypoglycemia observed in nondiabetics is abnormal in diabetics $(25,30,31)$, these observations pertain to the total glucagon response and separate analysis of phases of glucagon secretion has not been attempted. Possibly the early IRG response to glucopenia would be attenuated in the insulin-independent diabetics. Unfortunately, inadequately abrupt hypoglycemia cannot be accomplished with insulin administration to quantitate early IRG release in vivo.

Experiments to quantify acute phase insulin and glucagon secretion have usually employed very nonphysiologic techniques, and therefore the relationship of this data to insulin and glucagon secretion under the normal circumstances of feeding and fasting can be questioned. In fact, Lund et al. did not observe a biphasic insulin response to oral glucose in man even with frequent sampling from the portal vein (32). We postulate that $\alpha$ - and $\beta$-cells are continually modifying their secretory rates to the needs of the organism and that the presence of an intact acute phase secretory mechanism is the experimental representation of this ability to rapidly readjust secretory rates. Studies with the artificial pancreas have shown that changes in the rate of insulin delivery must occur very rapidly in order to correct the carbohydrate intolerance of diabetic dogs and patients $(15,16)$. In addition, we know that the $\beta$-cells in at least some adult-onset diabetics have lost the ability to respond rapidly to glucose $(7,8)$, whereas the absolute insulin levels reached during prolonged glucose stimulation are normal (12). Although our studies have shown that the $\alpha$-cell in diabetic patients responds acutely in a normal fashion to arginine, the possibility remains that to other stimuli, such as changes in glucose concentration, this early response may be abnormal and that this deranged timing of $\alpha$-cell secretion may also contribute to the carbohydrate intolerance of diabetes.

\section{ACKNOWLEDGMENTS}

The authors are grateful to Ms. Claudine Nist, Ms. Ellen Laschansky, and Ms. Martha Knoeber for their excellent technical assistance, and to Ms. Sharon Kemp for typing the manuscript.

A portion of this work was conducted through the Clinical Research Center of the University of Washington supported by National Institutes of Health grant RR-37. This investigation was supported by U. S. Public Health Service grants AM-16007, AM-13457, and Program Project grant HD-04872.

\section{REFERENCES}

1. Weir, G. C., S. D. Knowlton, and D. B. Martin. 1974. Glucagon secretion from the perfused rat pancreas. Studies with glucose and catecholamines. J. Clin. In vest. 54 : 1403-1412.

2. Iversen, J. 1971. Secretion of glucagon from the isolated, perfused canine pancreas. J. Clin. Invest. 50: 2123-2136.

3. Blackard, W. G., N. C. Nelson, and S. S. Andrews. 1974. Portal and peripheral vein immunoreactive glucagon concentrations after arginine or glucose infusions. Diabetes. 23 : 199-202. 
4. Fajans, S. S., J. C. Floyd, Jr., R. F. Knopf, S. Pek, P. Weissman, and J. W. Conn. 1972. Amino acids and insulin release in vivo. Isr. J. Med. Sci. 8: 233-243.

5. Porte, D., Jr., and A. A. Pupo. 1969. Insulin responses to glucose: evidence for a two pool system in man. $J$. Clin. Inzest. 48: 2309-2319.

6. Cerasi, E., R. Luft, and S. Efendic. 1972. Decreased sensitivity of the pancreatic beta cells to glucose in prediabetic and diabetic subjects. A glucose dose-response study. Diabetes. 21: 224-234.

7. Robertson, R. P., and D. Porte, Jr. 1973. The glucose receptor. A defective mechanism in diabetes mellitus distinct from the beta adrenergic receptor. J. Clin. Invest. 52: 870-876.

8. Varsano-Aharon, N., E. Echemendia, R. S. Yalow, and S. A. Berson. 1970. Early insulin responses to glucose and to tolbutamide in maturity-onset diabetes. Metab. Clin. Exp. 19: 409-417.

9. Simpson, R. G., A. Benedetti, G. M. Grodsky, J. H. Karam, and P. H. Forsham. 1968. Early phase of insulin release. Diabctcs. $17: 684-692$.

10. Deckert, T. 1968. Insulin secretion following administration of secretin in patients with diabetes mellitus. Acta Endocrinol. 59: 150-158.

11. Goodner, C. J., M. J. Conway, and J. H. Werrbach. 1969. Control of insulin secretion during fasting hyperglycemia in adult diabetics and in nondiabetic subjects during infusion of glucose. J. Clin. Ini'est. 48: 18781887.

12. Lerner, R. L., and D. Porte, Jr. 1972. Acute and steadystate insulin responses to glucose in nonobese diabetic subjects. J. Clin. Invest. 51: 1624-1631.

13. Palmer, J. P., and J. W. Ensinck. 1975. Acute-phase insulin secretion and glucose tolerance in young and aged normal men and diabetic patients. J. Clin. Endocrinol. Metab. 41: 498-503.

14. Lerner, R. L., and D. Porte, Jr. 1971. Relationships between intravenous glucose loads, insulin responses and glucose disappearance rate. J. Clin. Endocrinol. Metab. 33: 409-417.

15. Albisser, A. M., B. S. Leibel, T. G. Ewart, Z. Davidovac, C. K. Botz, and W. Zingg. 1974. An artificial endocrine pancreas. Diabctes. 23: 389-396.

16. Albisser, A. M., B. S. Leibel, T. G. Ewart, Z. Davidovac, C. K. Botz, W. Zingg, H. Schipper, and R. Gander. 1974. Clinical control of diabetes by the artificial pancreas. Diabetes. 23 : 397-404.

17. Palmer, J. P., R. M. Walter, and J. W. Ensinck. 1975. Arginine-stimulated acute phase of insulin and glucagon secretion. I. In normal man. Diabetes. 24: 735-740.

18. Metropolitan Life Insurance Company. 1959. New weight standards for men and women. Stat. Bull. Metrop. Life Insur. Co. $40: 1-4$.
19. Morgan, C. R., and A. Lazerow. 1963. Immunoassay of insulin: two antibody system. Plasma insulin levels of normal, subdiabetic and diabetic rats. Diabetes. 12: $115-126$.

20. Walter, R. M., R. J. Dudl, J. P. Palmer, and J. W. Ensinck. 1974. The effect of adrenergic blockade on the glucagon responses to starvation and hypoglycemia in man. J. Clin. Ini'est. 54: 1214-1220.

21. Snedecor, G. W., and W. G. Cochran. 1967. Statistical Methods. Iowa State University Press, Ames, Iowa. 6th edition. 1-593.

22. Valverde, I., R. Dobbs, and R. H. Unger. 1975. Heterogeneity of plasma glucagon immunoreactivity in normal, depancreatized, and alloxan-diabetic dogs. Metab. Clin. Exp. 24 : 1021-1028.

23. Felig, P., R. Gusberg, R. Hendler, F. E. Gump, and J. M. Kinney. 1974. Concentrations of glucagon and the insulin: glucagon ratio in the portal and peripheral circulation. Proc. Soc. Exp. Biol. Med. 147: 88-90.

24. Frankel, B. J., J. E. Gerich, R. E. Fanska, G. C. Gerritsen, and G. M. Grodsky. 1975. Responses to arginine of the perfused pancrease of the genetically diabetic chinese hamster. Diabetes. 24: 272-279.

25. Unger, R. H., E. Aguilar-Parada, W. A. Muller, and A. M. Eisentraut. 1970. Studies of pancreatic alpha cell function in normal and diabetic subjects. J. Clin. Inv'est. 49: 837-848.

26. Thorell, J. I., B. Nosslin, and G. Sterky. 1973. Estimation of the early insulin response to intravenous glucose injection. J. Lab. Clin. Med. 82: 101-110.

27. Müller, W. A., G. R. Faloona, E. Aguilar-Parada, and R. H. Unger. 1970. Abnormal alpha-cell function in diabetes. Response to carbohydrate and protein ingestion. N. Engl. J. Med. 283: 109-115.

28. Seltzer, H. S., E. W. Allen, A. H. Herron, Jr., and M. T. Brennan. 1967. Insulin secretion in response to glycemic stimulus: relation of delayed initial release to carbohydrate intolerance in mild diabetes mellitus. $J$. Clin. In'est. 46: 323-335.

29. Vinik, A. I., W. J. Kalk, and W. P. U. Jackson. 1974 A unifying hypothesis for hereditary and acquired diabetes. Lancet. I : 485-487.

30. Unger, R. H., I. L. Madison, and W. A. Müller. 1972. Abnormal alpha cell function in diabetics. Response to insulin. Diabetes. 21 : 301-307.

31. Gerich, J. E., M. Langlois, C. Noacco, J. H. Karam, and P. H. Forsham. 1973. Lack of glucagon response to hypoglycemia in diabetes: evidence for an intrinsic pancreatic alpha cell defect. Science (Wash. D. C.). 182: 171-173.

32. Lund, B., A. Schmidt, and T. Deckert. 1975. Portal and cubital serum insulin during oral, portal and cubital glucose tolerance tests. Acta Med. Scand. 197: 275281. 